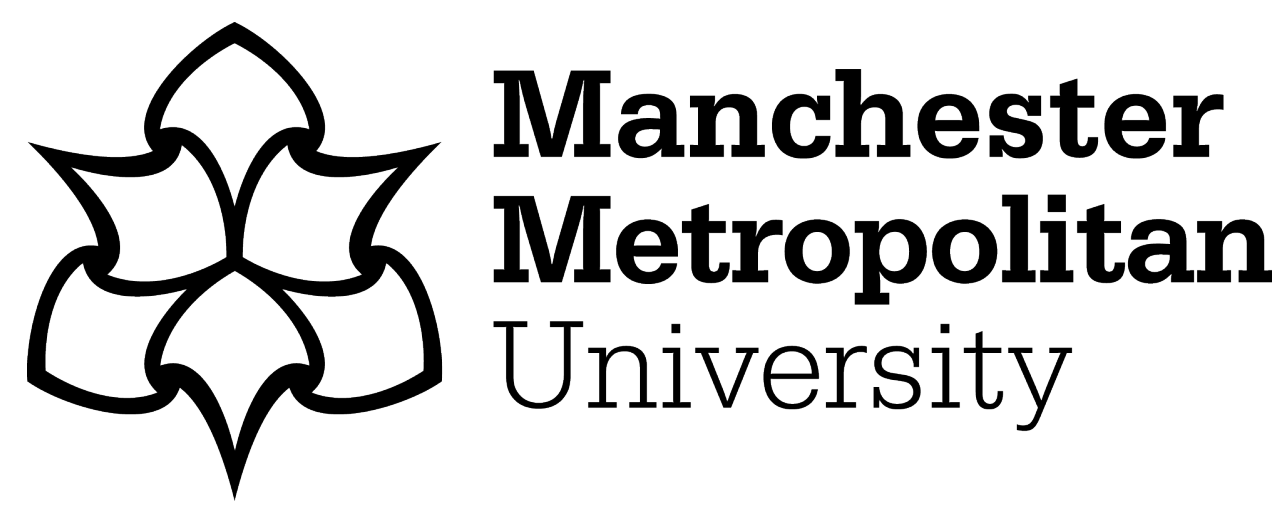

Nash, R, Yamada-Rice, D, Dare, E, Love, S, Main, A, Potter, J and Rodrigues, $D$ (2022) Using a collaborative zine to co-produce knowledge about locationbased virtual reality experiences. Qualitative Research Journal, 22 (1). pp. 7-23. ISSN 1443-9883

Downloaded from: https://e-space.mmu.ac.uk/628471/

Version: Accepted Version

Publisher: Emerald

DOI: https://doi.org/10.1108/QRJ-02-2021-0021

Usage rights: Creative Commons: Attribution-Noncommercial 4.0

Please cite the published version 


\section{Using a collaborative zine to co-produce knowledge about location-based Virtual reality experiences}

Richard Nash, Dylan Yamada-Rice, Eleanor Dare, Steve Love, Angus Main, John Potter and Deborah Rodrigues

\section{Purpose}

This article focuses on a designed research methodology to distil existing research findings from an ESRC/AHRC funded Japan/UK network on location-based Virtual Reality (VR) experiences for children in order to generate new knowledge.

\section{Design/methodology/approach}

The structured co-production methodology was undertaken in three stages. These were: (1) a collaborative workshop which produced a series of collage narratives, (2) collaborating with a non-human entity in the form of a digital coded tool to reconfigure the workshop responses and mediate the hierarchy of roles, (3) the co-production of a zine as a collaborative reflection method, which shared via postal service enabled a dialogue and exchange of round robin interventions by the network members.

\section{Findings}

The analysis of the data collected in this study highlighted five themes that could be used by other researchers on a wide range of projects. These were: (1) Knowing through making, (2) The importance of process, (3) Beyond linear representations, (4) Agency of physical materials, (5) Agency of digital code.

\section{Research limitations/implications}

The context of the study being undertaken during the first phase of the global pandemic, revealed insight into a method of co-production that was undertaken under emergency remote working conditions. The knowledge generated from this can be applied to other research contexts such as working with researchers or participants across global borders without the need to travel.

\section{Originality/value}

The research provides an innovative rethinking of co-production methods in order to generate new knowledge from multidisciplinary and multimodal research.

Keywords: Collaborative Zine, Collaborative Tool, Co-producing with non-human entities, Coproduction and automation, Co-production and remote working, Remote-working and collaborative tools, Artists' books, Narrative collage, Multimodal approaches

\section{Introduction}

This article outlines a co-production project conducted during the 2020 COVID-19 lockdown period. The methodology was designed by Richard Nash to focus on distilling existing research findings and to generate new knowledge from an ESRC/AHRC funded Japan/UK network project that explored location-based Virtual Reality (VR) experiences for children (YamadaRice et al, 2020). Nash had not participated in the original network but sought to join at the end of the project to investigate how his practice-based research methods centred on the creation of original artists 'books and publications could potentially bring additional benefits to a completed study. This extended on previous research Nash had undertaken to create the artists' 
book On Innards Publication (Couch at al, 2015), which was the product of his engagement across the duration of a previous research study. The intention was to understand how methods used in the production of artists' books could bring benefits to research in different disciplines, and in particular to multidisciplinary contexts, in ways traditional means of data analysis and dissemination are unable to do.

The project started with an initial workshop delivered in April 2020 via the online platform Zoom. This workshop employed a narrative collage methodology (Kostera, 2006) and asked an established group of six researchers (Deborah Rodrigues, Angus Main, Dylan Yamada-Rice, Eleanor Dare, John Potter and Steve Love) to share reflections on a network study they had just completed. This was achieved through a series of image-making and storyboarding exercises. The methods discussed in this article were developed to extend beyond traditional concepts of co-production to consider how a non-human entity in the form of a piece of opensourced digital code produced using the software Processing 3 might bring additional benefits. The exercises and coding were designed to disrupt the way the researchers thought of the themes that had emerged from the research data undertaken with established means of analysis.

In relation to using a non-human digital entity in the co-production process, Brandsen (2019) states that there is little empirical evidence of the effects of new technologies in co-production. Case studies on non-human entities in co-production often focus on the impact of digital technology in relation to wearable and smart technology, communication, processing and actuation. As stated by Young et al (2011), robot-human interaction is often limited to facilitating human-human interaction, or at best can influence co-production patterns indirectly. This study reveals new approaches to human-machine interactions where the collaborative tool is an active participant in the co-production process. It shows how the code created in Processing 3 facilitated secondary analysis of the original research data findings that were achieved through the use of Thematic Analysis (Braun and Clarke, 2008) and furthermore mediated the hierarchy of roles in the co-production process.

The article is structured to focus on the literature in relation to the artists' book, and the role of the artists' book as a primary medium for the creation and dissemination of scholarly research. Next, details of the methodology and means of analysis are shared. Following this, the findings are discussed in relation to five areas. These are: (1) Knowing through making, (2) The importance of process, (3) Beyond linear representation, (4) agency of physical materials and (5) Agency of digital materials

\section{Artists' Books in Research}

For an audience who might be unfamiliar with the term 'artists' book' the intention of this literature review is to provide background and context. What constitutes an artists' book and its lineage as a field of practice has been widely discussed, notably by Lyon (1987), Castleman (1994), Bury (1995), and Drucker (2004). The earliest precedents of the artists' book are of some debate. While these have included discussion on bookworks by William Blake and even Leonardo da Vinci (Silveria 2001), it is Henri de Toulouse-Lautrec's (1894) Yvette Guilbert (Castleman, 1994) and Blaise Cendrars and Sonia Delaunay-Trek's (1912) La Prose du Transsibrien et de la petite Jehanne de France (Bodman, 2017) that are often cited as forerunners of the medium. It could also be argued that the first 1914 publishing in book form of Stephanie Mallarm's, Un coup de des jamais n'abolira le hasard, could also be included in this list amongst others. The commonality of what defines these examples is what Sassen (2017) states is 'the issue of simultaneity in text, illustration and binding'. While avant-garde 
experiments during the first half of the 20th century are critical to the discourse, it is broadly agreed that during the 1960's practitioners Dieter Roth and Ed Ruscha, with very different concerns within the medium, are held as precursors to the contemporary artists' book.

From entrenched positions and concerns that differentiate emphasis on aspects of form, process, dissemination and archiving, there are many definitions for what constitutes an artists' book, and in comparison to adjacent forms of self- and small-published works, e.g., experimental publications, art books, exhibition catalogues, altered books, sculptural books, photobooks, illustrated books, graphic novels, zines, hypertext and other digital formats. For the benefit of this study, the format of a zine is used not as an output but as an open-ended coproduction method, in which the generated insights and materials will inform a further process of developing an artists' book. The rationale for the term zine in this instance is derived from what Thomas (2009) discusses in the context of a larger do-it-yourself (DIY) movement, including; crafting, home building, scrapbooking, and other such activities. In this study the zine was intended as a continuation of the co-production process and an opportunity for the participants to continue to interact with the data and to extend their reflections in different modes.

Milne (2019) argues that what makes the artists' book unique is its resistance to definition, and as such, arguably, has a unique relational position in constantly bordering with otherness, while also always retaining the essence of bookishness. Broadly situated within fine art practice, the artists' book also appropriates discourses from graphic design, typography, publishing, photography, literature and creative writing (Bodman, 2017) as well as arguably individual examples that span a vast range of disciplinary connections. It is in their 'mongrel nature' (Burkhart, 2006) that the artists' book transcends cultural practices to reveal different systems of representation and engagement (Milne, 2019). It is the qualities of hybridity and mobility that affords the artists' book a unique perspective in the creation and dissemination of knowledge.

The reflexive and performative quality of the medium is of importance to what constitutes an artists' book, and its unique position and potential. Adema (2018) discusses correlations between Hayles' (2002) concept of the 'technotext' and Drucker's (2013) notions of 'performative materiality' and 'liberature' (Fajfer, 2010) in the development of 'hypothes.is' (an open-source browser extension) as 'performative publishing', with the purpose of exploring the 'ethical and political challenges towards academic publishing these kinds of concepts and practices pose'. Adema $(2018$, p.80) expands on this by stating that, "If performative publications are the material expressions or incarnations of specific research projects and processes, entangled with them are various other agencies of production and constraint... What I want to argue is that performative publications as a specific subset of publications actively interrogate how to align more closely the material form of a publication with its content (in other words, where all publications are performative - i.e. they are knowledge shaping, active agents involved in knowledge production - not all publications are 'performative publications', in the sense that they actively interrogate or experiment with this relation between content and materiality".

It is in this respect that Adema (2018) argues that the artists' book as a primary medium offers potential beyond many conventional norms as a method of knowledge production. Milne (2019) discusses the artists' book as analogous to scientific inscriptions. In defining the notion of 'inscriptions', Milne quotes Latour (1999, p.4), stating that the 'transformation' and 'materialisation'... 'into a sign, an archive, a document, a piece of paper, a trace... designed to 
transmit information or ideas corresponding to an entity within the science nexus'. This could be compared to Drucker's (2004, p.12) classification of the 'hybrid genre of the catalogue as artists' book'. Milne (2019) builds on anthropologist Alfred Gell $(1992$, p.1) in discussing the artists' book form as a 'technology of enchantment'. Milne $(2019$, p.4) also refers to this as an 'unravelling' and 'cognitive stickiness' through which the recipient mediates 'the intentions [of the artist]... embedded in the words, images and objects and surfaces of the book but also within the sensorial experience of the reading'.

In discussing the performative potential of the artists' book, Adema (2018) highlights the potential for problematizing notions of reading and authorship. In artists' books this act of reading is visual, haptic and temporal. With a multiplicity of forms, the artists' book invites a multi-sensory and alternating process of reading/viewing/touching; be it through a turn of a page, the unfolding of a container, or the swipe of a tablet, amongst engaging with many other physical, digital or multiplatform formats. Milne (2019, p.5) describes this haptic experience as reading with 'eyes, ears and fingers', in which the process of engaging with the form of the book can 'incorporate dissonant textures, weights and sounds, and these shifts suggest rather than point to an established or fixed narrative'. Frost $(2005, \mathrm{p} .1)$ refers to 'touch as a mode of communication' and 'the aesthetic consequences... in the hands of the reader where tactile qualities and features of mobility are appreciated'. The shifting perception of the recipient in activating the form and content unlocks the potential for simultaneous processes; an unfolding of multi-sensual, non-linear, and intertextual relations. It is this unique set of properties that the artists' book has the potential to create a new performative space for complex ideas, and important to this research, a relational and conceptual space between the artists' book and AR, VR and other immersive experiences.

Critical to this discussion is the quality of mobility to offer a potential method for disseminating research. Adema (2014) argues that the unique qualities of the medium offers a 'reimagining of what counts as scholarship and research, and of how it can be responded to and accessed'. This argument is founded on the artists' books history rooted in the avant-garde's exploration of the book as a radical departure from gallery and museum structures and taken further during the mid to latter 20th century against the backdrop of social and political activism (Drucker 2004). Drawing on the history of independent publishing platforms, Milne (2018) discusses the international presence of contemporary book fairs as 'nodes for dialogue' and as purposeful for expanding audiences. In contrast, Adema (2014) proposes a radical and political position for the artists' book as 'open access', challenging conventional routes and norms of publishing academic research.

This poses a number of questions regarding aspects of rigour, peer review, and so on, that have anecdotally been used to argue against self-publishing in academia by characterising it as vanity publishing. As Adema (2014), Bodman (2017) and Talyor (2018) would argue, and as discussed in this study, there is no reason why self-published artists' books cannot meet the same academically credible standards as other works. Furthermore, they have the potential to open up research, especially research that is situated beyond art and design disciplines, to new communities of practice and audiences beyond academia

\section{Methods and Means of Analysis}

\section{Study Design and Methods}

The intention of this study, as the first part of a two-phase methodology for creating an artists' 
book, was to use the process of co-producing an initial collaborative zine to understand the extent to which it would be useful as a research method for furthering the knowledge gained from a completed research study. The study in question was an ESRC/AHRC funded Japan/UK network focused on location-based Virtual Reality (VR) experiences for children. The coproduction of the zine as a method of developing an artists' book involved six researchers from the UK side of the network (Potter, Yamada-Rice, Rodrigues, Main, Love and Dare) who were led through a series of workshops and activities by Nash whose research focuses on the multidisciplinary and collaborative nature of artists' books. Importantly, Nash was unfamiliar with the original research network outcomes. In this way, he was able to instigate the methods and bring together the zine without being concerned with the prior study on which the contents were based.

This study outlines four stages; (1) a collaborative collage narrative workshop, (2) the production of a zine in collaboration with a non-human entity in the form of a piece of digital code, (3) a round robin stage of interventions to the printed zine, and (4) individual interviews with each of the researchers about their reflections on the methodology.

\section{Collage Narrative Workshop}

The first stage was an online workshop that took place on Zoom. Nash provided each of the six participants with a series of purposefully designed A4 storyboard templates to guide a series of ideation and drawing / image making tasks (Figure 1). The dimensions and scale of the different panel configurations were designed on an equivalent modular grid for the ease of combining each of the participant's outcomes. Working from prompts provided by Nash, the group were asked to reflect on the themes established within the research report. For the purpose of the study, the narrative collage method was adopted to reflect on and approach the established research differently.
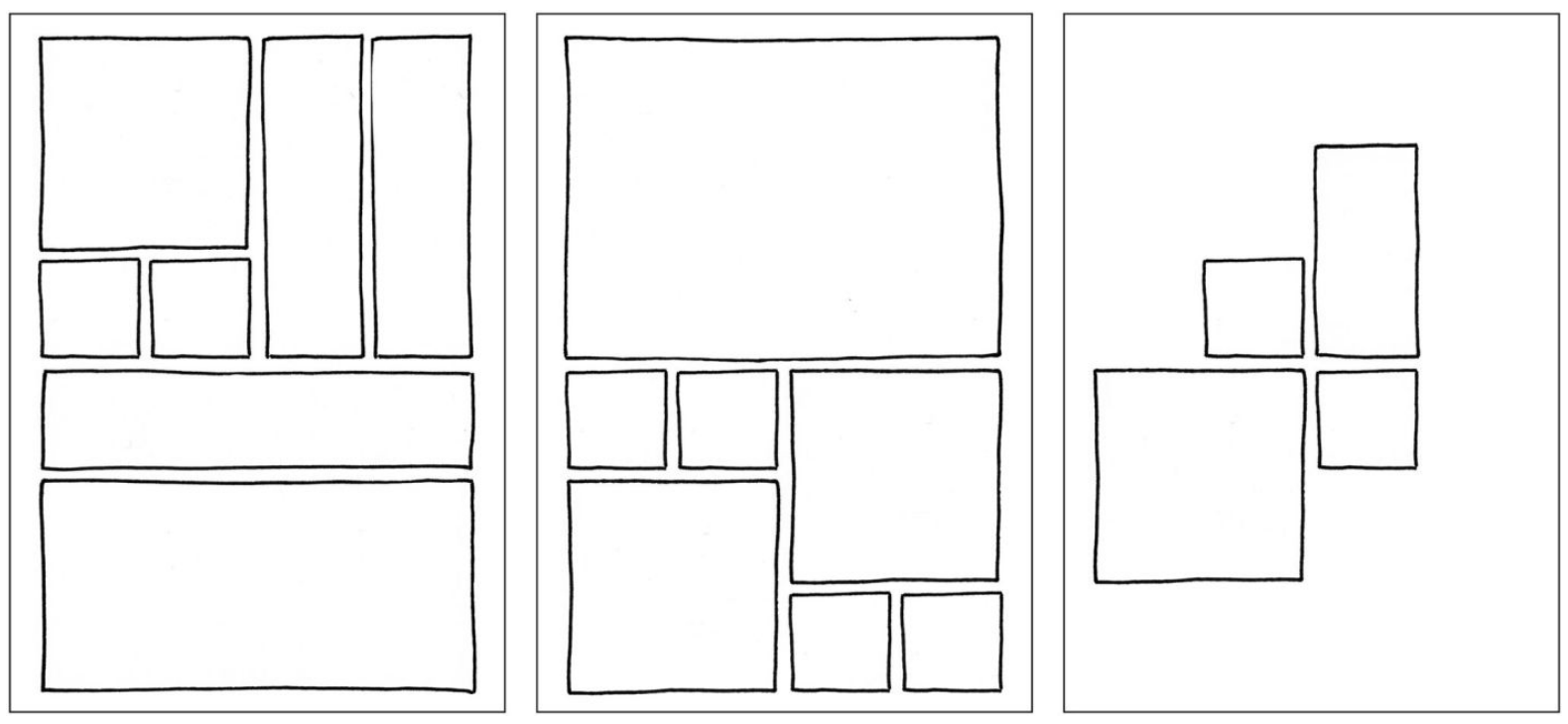

Figure 1: Workshop storyboard templates

Each workshop participant was asked to fill in the panels to reflect their personal recollections and anecdotes of their experiences of activities, events, or situations during the original VR network (Figure 2). Anecdotal evidence goes against accepted methodological norms but the approach in this project was to use it as a valuable construction phase. Important for the 
research study, the openness of the method allowed the participant group to express ideas that lay beyond fact, to what Kostera $(2006$, p.10) states 'is to approach the subjective sphere closer to feelings and imagination than to solid fact'. The method also allowed for a blurring between fiction and reflection, which was valuable for the researchers to express their experiences of location-based VR, which existed partly in physical and virtual spaces and combined fact and fiction in many of the narratives.
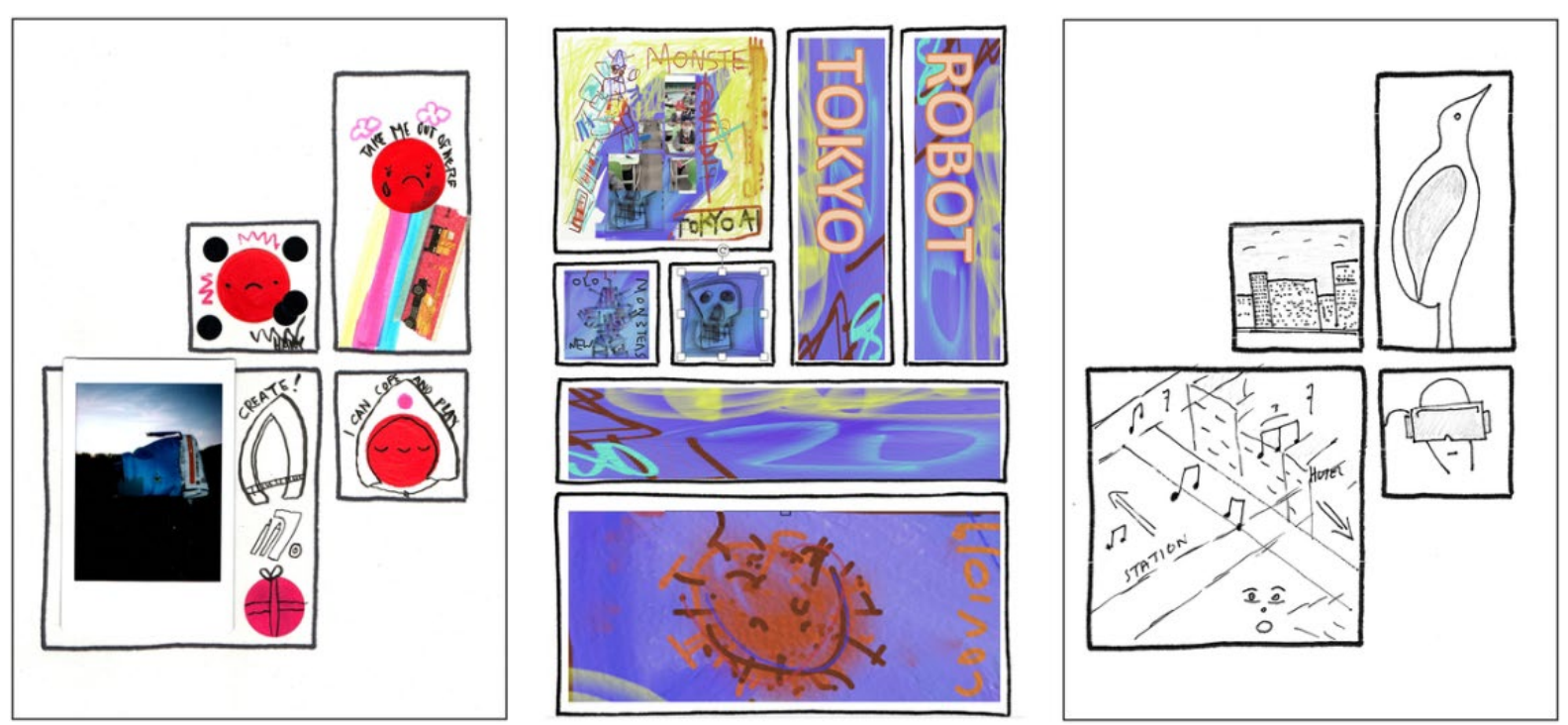

Figure 2: Participant storyboard responses

\section{Collaborative Tool}

As a result of the emergency measures of remote working introduced in March 2020, methods were developed further to facilitate co-production within an online environment. A piece of opensource code built in Processing 3 (Batrack, 2018) was modified for the purpose of enabling a digitally mediated method of separating and recombining the individual panels in each participant's workshop responses. The design of the research method integrated the use of the code as a 'collaborative tool' to automate the process of generating new configurations at speed and importantly without them being formed by any of the people in this project (Figure 3).
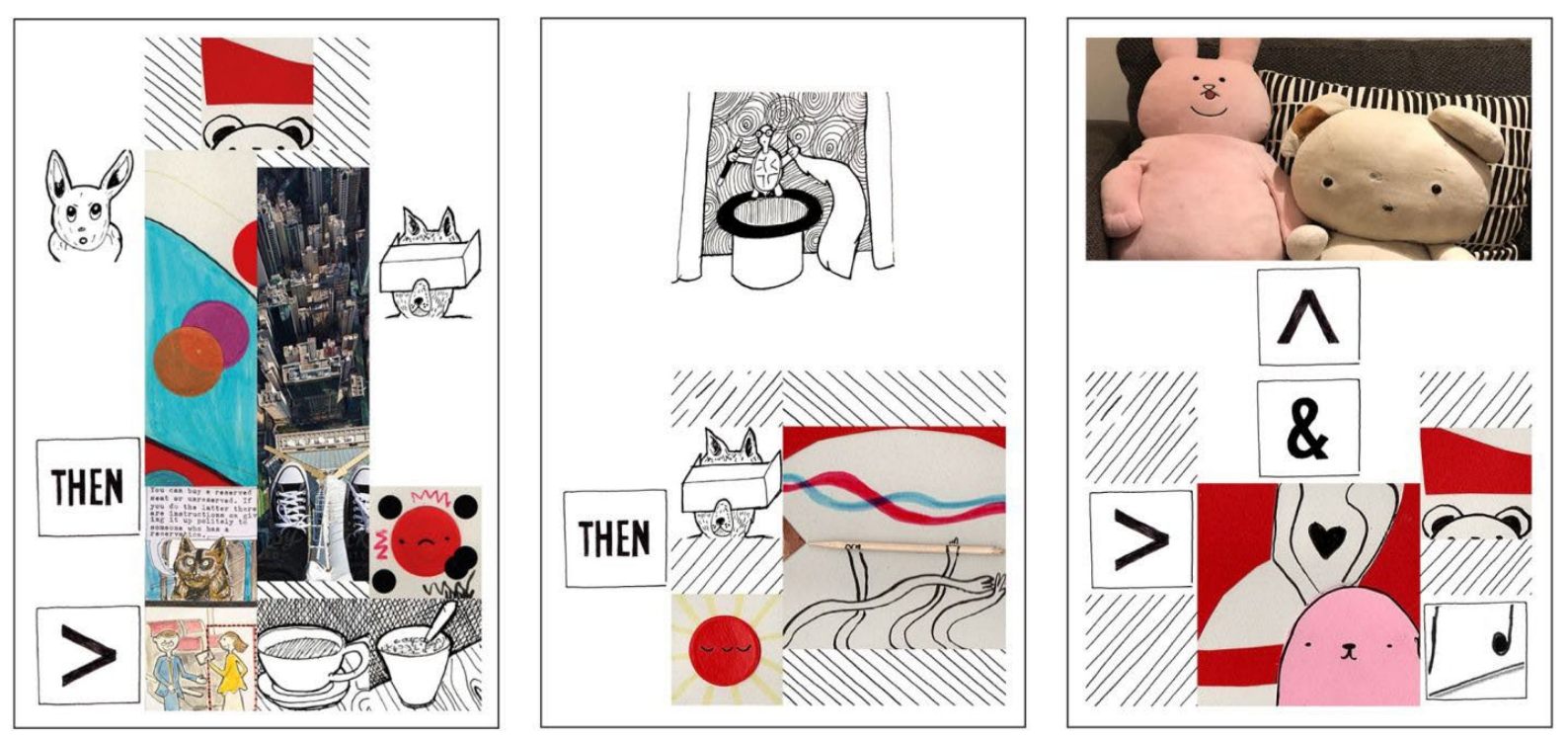
Figure 3: Examples generated layout combinations

As part of the structured co-production methodology, the role of the collaborative tool can be evaluated in relation to what Young, et al (2011, p.54) define as an 'affect-charged sense of active agency similar to that of living entities'. In drawing parallels to Nyholm's (2017) analysis of human machine collaboration, the collaborative tool omitted intentionality; its parameters were defined in the design and also extended to its supervision. Nyholm (2017, p.1206) refers to this as the 'responsibility-gap' in the collaborative agency in situations of human-machine interaction. Rice (2017) argues non-humans have a role configuring the social and increasing the level of participation in a design process. In doing so they can mediate the roles in participation and increase democracy within the process.

The process of deconstructing and reconfiguring individual panels created a fragmentation and modularisation of the shared reflections with a vast number of potential configurations. This process created non-sequitur combinations creating new connections with a high degree of chance. The non-sequitur structure also aligned to aspects of the existing research study investigating the visual language of Japanese and American comics and their inherent differences as sociocultural artifacts (McCloud, 1993, Cohn, 2010). As defined by McCloud (1993), non-sequitur relationships do not contain logical connections. By placing disassociated images in proximity means that humans automatically begin a process of looking for connections. Anchorage of text and image relationships were also considered through the inclusion of hand rendered typographic devices. Combining with the collection of generated data assets, these were intended to punctuate and potentially reframe relationships between images and the sequence as a whole.

\section{Zine Production}

Secondary analysis of the generated storyboard combinations informed the critical selection process, curation, and production of a bound zine. Two editions of the zine were created. An initial pamphlet stitched approximate A5 scale edition (Figure 4), and a larger approximate A4 scale edition (Figure 5), which included extracts from the Japan / UK Knowledge Exchange Network Report on Location-based Virtual Reality Experiences for Children (Yamada-Rice et al, 2020).

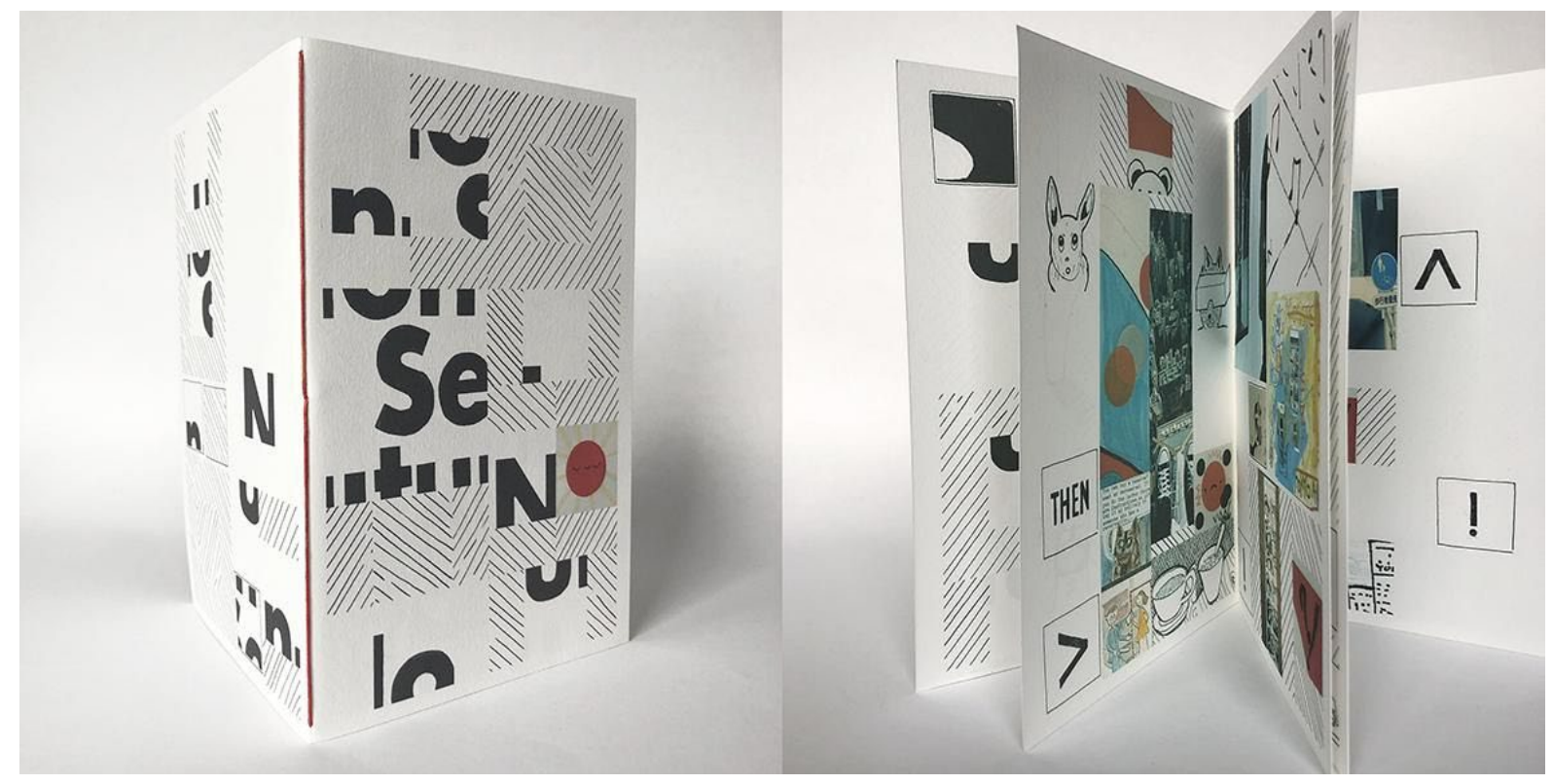


Figure 4: Edition 1.0

\section{Round Robin Additions}

The zine was shared via physical mail as a series of round robin interventions. This process focused on developing an exchange and dialogue, reinforcing new connections and revealing further findings. The language and materiality of the zine made space for the expression of different perspectives as well as interventions through a wide range of media and modes of working; from marginalia, to visual, material, and audio responses. Continuing beyond this article, it is intended that all participants will receive the zine twice as an outbound and return journey.

This process of exchange will then be extended to the Japan side of the network before an intended point of consolidation, analysis and further workshops. Once completed, this body of coproduced material will form the basis for further analysis and critical engagement to inform the development of an artists' book. As shown in Figure 5, so far interventions have included a series of textual, graphic, and material interventions as well as the inclusion of QR codes linking to a series of experimental videos and audio soundscapes.

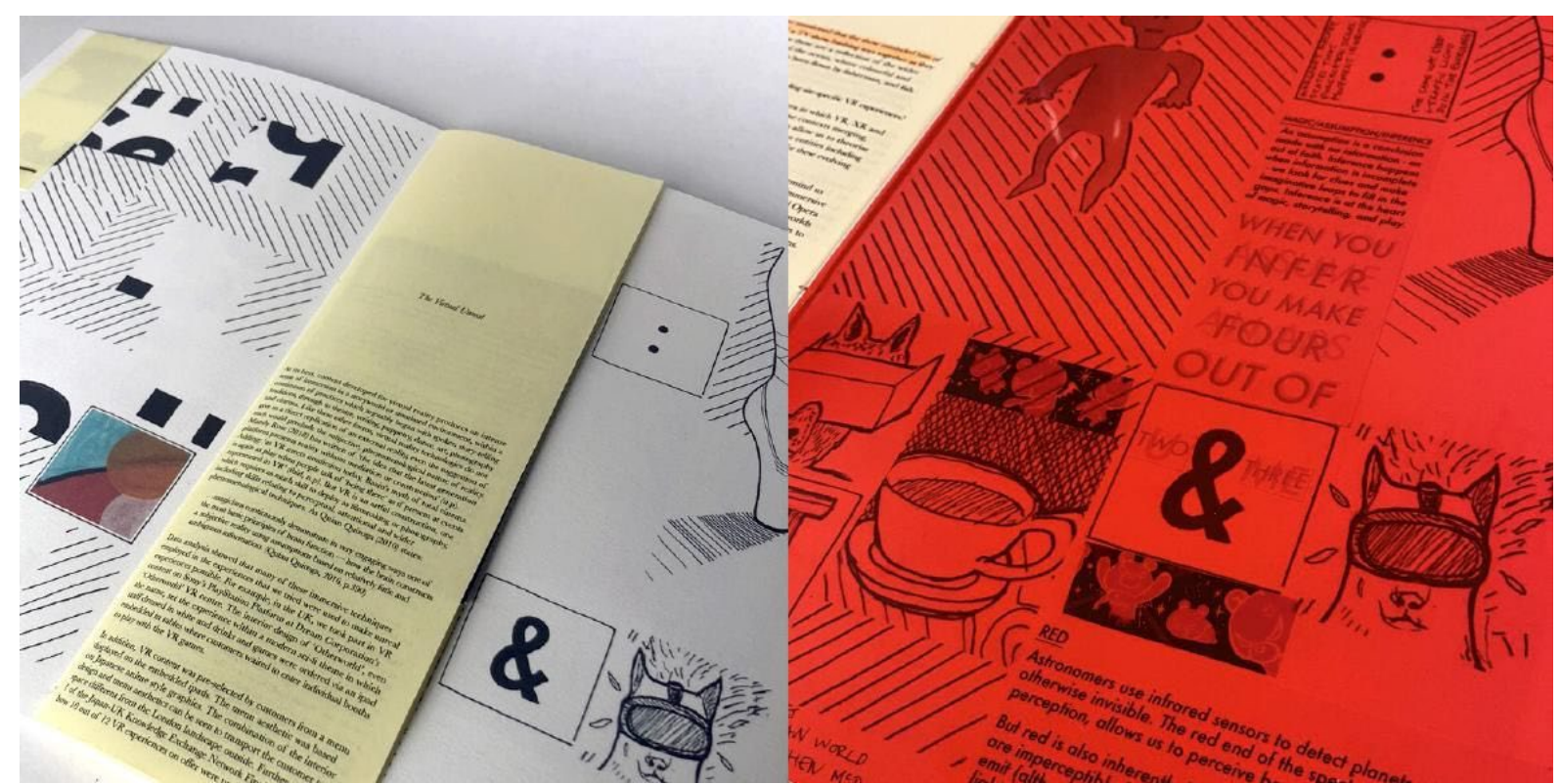

Figure 5: Spread edition 2.0 of Non-Sequitur (left). Example layering of different participant's interventions (right)

\section{Interviews}

After the workshop Nash undertook individual interviews with the workshop participants. The interviews took place one-to-one on zoom and a number of questions were asked in order to understand the usefulness of the methodology at each of the three stages (Table 1):

\begin{tabular}{|c|c|}
\hline Project Stage & Interview Question \\
\hline \multirow[t]{2}{*}{$\begin{array}{l}\text { Stage 1: Narrative collage } \\
\text { workshop }\end{array}$} & $\begin{array}{l}\text { 1. How useful was the narrative collage method } \\
\text { to reflect on your experiences, activities, or } \\
\text { situations undertaken during the original } \\
\text { research? }\end{array}$ \\
\hline & 2. How did you approach the tasks set? \\
\hline
\end{tabular}




\begin{tabular}{|l|l|}
\hline \multirow{3}{*}{ Stage 2: Collaborative tool } & $\begin{array}{l}\text { 3. Did this process reveal new connections } \\
\text { within the } \\
\text { existing analysis and findings? }\end{array}$ \\
\hline & $\begin{array}{l}\text { 1) How would you describe your experience of } \\
\text { working with a collaborative tool to mediate the } \\
\text { process of co-production? }\end{array}$ \\
\cline { 2 - 3 } $\begin{array}{l}\text { 2) Did the process of reconfiguring the } \\
\text { outcomes } \\
\text { reveal new connections? }\end{array}$ \\
\hline $\begin{array}{l}\text { Stage 3: Zine as a reflection } \\
\text { method and round robin }\end{array}$ interventions & $\begin{array}{l}\text { 1) How has the zine format facilitated further } \\
\text { work with the generated data? Are there specific } \\
\text { instances of new combinations / affordances / } \\
\text { signifiers that influenced how and why you } \\
\text { responded? }\end{array}$ \\
\hline & $\begin{array}{l}\text { 2) Has the process of working with the zine } \\
\text { format revealed anything new within research } \\
\text { and also the process of co-production? }\end{array}$ \\
\hline
\end{tabular}

Table 1: Interview Questions

\section{Data and Analysis}

The data took four forms; (1) the images produced in the collage narrative workshop, (2) the zine in its original state and after it had been added to, (3) transcribed data from the interviews, and (4) chat from a WhatsApp group across the duration of the project. These were analysed by applying thematic analysis (Braun and Clarke, 2008) to the written data and then using these themes to apply visual content analysis (Aiello, Parry, 2019) of the visual data set. The findings are presented next under core themes that emerged from these by means of data analysis.

\section{Findings and Discussion}

The findings and discussion are divided into five subsections that relate to core themes that emerge from the data analysis. These are; (1) knowing through making, (2) importance of process, (3) beyond linear representation, (4) agency of physical materials, and (5) agency of digital materials.

\section{Knowing Through Making}

Ingold (2013) writes about the history of human's relationship to making as a means of meaning making and knowledge construction. Relatedly, our data illustrated how the hands-on activities of this project that used drawing, cutting, sticking and editing sound also provided a means for knowledge generation:

"Through the step-by-step activities that led to the creation of the initial image set for the zine, I found that it became a tool to think with." (Potter)

Souansis' (2015) graphic novel based on his doctoral research about knowledge construction and modes illustrates how drawing in relation to academic research allows a different type of knowledge to be foregrounded. Later, Sousansis (2017) extends this idea to suggest graphic narratives are a suitable medium for exploring complex ideas. Yamada-Rice (2021) shows that this argument is important to research about Virtual Reality experiences, which are multifaceted consisting of both simultaneous engagement with physical and virtual worlds, 
virtual characters and fellow players, as well as, the combining of physical and digital technologies.

Kress (2010) writes that each mode of communication, such as image, sound or writing comes with its own set of possibilities to make certain parts of information visible. This Kress relates to 'affordances', the properties of each mode that convey or constrain the information. For example, writing in the English language is a linear process that prioritises combinations of subject and action. In contrast, the visual mode shows spatial relationships between subjects and/or objects (Kress \& Van Leeuwen, 2006). Yamada-Rice described how the mode used for disseminating responses to the VR network research changed the way she began to construct and represent her ideas:

"When I write I'm trying to think about things I've read and how my ideas relate but when we were doing that workshop, I was kind of looking around my room... and my eyes would fix on something that I picked up in Japan, like one of those little Gacha Gacha toys, and, again, this wouldn't have come up through the process of writing because the way of thinking and then trying to get the information down is fundamentally different. So, I think it did reveal new things. " (Yamada-Rice)

In this way thinking through writing appears to connect to other written references but with drawing it is linked to visual materials and objects. Likewise, Main described how he used other visual references to begin the process of drawing which was different to his writing processes:

"I'm not confident drawing so I'm not [able] to draw from imagination, to be able to bring pictures into my mind and then sort of externalise it graphically is not something I can do by hand." (Main)

As a result, Main described how he returned to look at photographs he had taken in Japan as sources for his collage narratives. Such processes were valued by the team as part of the making and what that meant for knowledge construction.

\section{The Importance of Process}

The zine can be classed as a prototype for exploring the research experience and an experimental space for its representation. Ware (2010, p.267) writes that the role of prototypes 'in knowledge transmission has long been overlooked in the arts and sciences'. However, analysis of the reflection of the zine co-production experience demonstrated that the process rather than the product was what became valued:

"I found the process really compelling and interesting, though I was daunted initially by the thought of drawing... not having a fine art background became less and less of an issue as the workshop progressed. The whole thing became far more an exploration of process rather than an overarching concern with product." (Potter)

Buchli (2010) describes the long history of prototyping which includes early Christian prototypes in the Byzantine iconographic tradition; the rise of rapid prototyping in 20th-century industry; and the emergence of rapid manufacturing in the 21st century. In all these forms Buchli (ibid, p.273) states, prototypes share commonality in the ways in which they can be 
used 'to produce and present the immaterial and thereby create novel forms of social and material life'.

The nature of collaborating and working as a group on one output was fundamentally linked to the co-production process. Rodrigues noted that this social aspect produced a compelling energy that helped the process:

"For me it was exciting to share that moment [the workshop] where everybody is doing [making]. It was like we were all tuned into a frequency and everything was heightened." (Rodrigues)

The joining of ideas across the group members was talked about in the interviews and evident in the zine. Rodrigues said "I used a red dot because that is like Japan [flag]". In a separate interview, Yamada-Rice said she didn't recognise the dot as the Japanese flag but the colour made her pick up on red symbolism in Japan and thus she began colouring relevant iconography with a red pencil. When Main received the zine, he used red as his starting point too:

"I was thinking about red filters and about how I could use red acetate as a tool to create engagement." (Main)

Specifically, Main sought to bring about audience engagement by using a decoder method of applying a red acetate overlay to hide and reveal information typeset using red and cyan text. This was a trick gained from a Japanese children's book he bought as a souvenir for his children during the original research field trip to Japan. Threads such as the one described above can be interpreted as 'lines' which Ingold $(2007$, p.1) state are a common means of meaning making 'as walking, talking and gesticulating creatures, human beings generate lines wherever they go'. Such care was also linked to an awareness that we were all co-producing a shared experience. Norman (2013, p.10) provides an indication of why this might have been important, 'experience is critical, for it determines how fondly people remember their interactions'. As will be shown next, the experience was valued for being multimodal and non-linear.

\section{Beyond Linear Representation}

The co-production zine activities required re-engagement with the VR network project after it had been completed. To do so, the participants described trawling through multisensory memories which were attached to the nature of the project. That is, both in undertaking VR related activities that use sound, image, and touch, as well as the Japanese context for the study. These memories were multimodal in nature, that is how a combination of resources beyond writing such as image and sound formed their experiences (Kress, 2010), and thus highlighted the limitation of writing in the prior network dissemination:

"But the blog post [used to record reflections on the research project before the zine] was able to convey only so much of the experience... I was wondering how to get the sound of the experience into the work, because for me Tokyo itself was a virtual reality experience." (Potter)

Potter is a musician and thus he is attuned to audio. Others in the group also talked about the benefits of using modes that are aligned with their own creative practices: 
"I'm interested in the process of world building as a method and methodology, critically

and technologically, and with that, I include drawing, particularly with collaboration. I think these are good heuristics for thinking through our thoughts in a non-directed way, in that type of space where you're allowed to meander in conversation." (Dare)

Likewise, when Rodrigues referred to the drawing in the collage narrative workshop she said:

"It didn't require so much thinking. For me, it's my favourite way of expressing myself." (Rodrigues)

Bezemer \& Kress (2015) describe how modal selection brings 'gains and losses', that is with every modal choice an author makes, something is gained and something is lost from the representation of information:

"You could, arguably, narrate a straightforward account of what happened to you when you put on some goggles and move into a VR experience, but a description which encompasses seeing through your headset into some other space (that isn't really there) as a series of layers or laminates gives a more accurate picture of the affective experiences you have." (Potter)

The use of modes beyond writing which do not have linear properties evoked a reminder of the original Japanese research field more widely and allowed the group to connect the project to aspects of 'being in the field' that had seemed less important in the written final project report but now seemed to be connected:

"Our experience of the world... is not strictly linear. Time flashes backwards and forwards, and memories and impressions and imagined images come into play. So, turning the pages of the zine...sticking things into the zine, and talking about the zine initially in that workshop, was very much analogous to looking again at those layered aspects of VR and... being somewhere different. In that way it's not a diary account of going to Japan... It's an attempt to represent all of the layers of experience at once. It is all-encompassing in the same way as putting on the VR headset and entering a world. It doesn't come across as much in the blog as I hoped it would, whereas in the zine, or certainly in the experience of making the audio, and later the video for the zine, it really does." (Potter)

In other words, the co-production of the zine was making the multiple layers of the VR network more visible. In part this was due to the material layers in the zine. Main suggested that the physical layers of the zine made it possible for everyone to find an entry point to begin adding:

"There was also something about the format. It has inserts, smaller pages, written text and larger pages. It was all a lot of material- a kind of friction in a way-something you could play with. It wasn't all one kind of thing. " (Main)

The above quote identifies the additional social layers of the zine. This is also emerged in relation to the collage narrative workshop:

"I think we were talking about the 'unreal' [from the original project] and I was looking at Deborah [Rodrigues]... it reminded me of checking into a hotel. Deborah 
had her teddy with her and the people who were checking us in were like, welcome, welcome, welcome to the teddy, not to us, and then whisked the teddy off saying we've got a perfect companion and there was this other teddy rabbit on the sofa in the reception area, and that really connects to the unreal for me. I wouldn't have written this up in the report because people would think, well, that's a really anecdotal irrelevant story, but actually it reminded me again that the unreal was one of the themes that emerged from the analysis of VR content in Japan." (Yamada-Rice)

This example shows how these various layers, the materials, and the social extended the themes from the original network project. However, Dare cautioned that the zine was still a representation and did not do complete justice to the experiences that had been shared through mutual exploration of location-based VR experiences:

"What is lost is the physical collaborative experience we had in VR, which was very powerful, such as being on a magic carpet platform, moving and seeing the pictures of me and Debbie on a flying carpet, it was very, very physical. It's not something you would experience or completely could articulate through language, particularly the gut feeling of it, the lurching and proprioception. Those are the kinds of things that are not there, in the zine. It's a different type of representation." (Dare)

\section{Agency of Physical Materials}

Researchers from several disciplines have theorised how materials have as much agency as humans. These include object ethnographies (Carrington, 2012), artefactual literacies (Pahl and Rowsell, 2010), object-orientedness (Kaptelinin et al., 1999), and material stuff (Miller, 2008, 2009; Shove et al., 2007) and that materials are themselves vibrant matter (Barad, 2003). One of the themes to emerge from the data was how the various constructs of the physical materials in the workshop and subsequent zine played a role in what knowledge was made visible. Once the zine was printed its agency became more precious. Main noted that the original instructions that came with the zine when it arrived in the post were written in the first person.

While made from discarded materials and employing low-tech printing methods, the design and handbound finishing of the zine seemed to require a level of respect. In relation to this, each of the three participants who added to the zine (before it was lost) described taking their time to plan what they wanted to add:

"I added different kinds of washi tape. I wanted to remind the others who would receive the zine of the feeling of being in the Japanese stationary shop. This was not part of the research focus on VR but ...for me the tape encapsulates that experience from the network, a group of researchers who did not all know each other at that time as well as we do now." (Yamada-Rice)

Likewise, Main also took his time working out how to add to the zine. As was described above, he was also influenced by experiences from Japan that did not directly relate to the VR focus of the original network study. This was highlighted by his inclusion of red acetate which he stitched into the zine:

"It was this really beautiful object. It was really well made and a really nice collection of all our different memories.... everyone who has had it has taken their time. It feels 
like something you need to do properly so I went about planning it quite carefully." (Main)

The agency of the zine was elevated by the way in which it travelled from person to person via the postal system:

"I think the zine did have agency when it was traveling around. The zine itself was awaited and was expected and it arrived, and it came with a bundle of stuff, [inserts, writing, etc.] ... And then I added in the things that I made offline and the things I'd made online, and then I put them both in there and added some drawings and sent it off. It is in that way; I think the zine itself does have a character and it does have some agency in this and we've surrendered a bit of ourselves to it." (Potter)

This was displayed fully when the zine got lost:

"Certainly, for the period during which the zine was travelling between team members and ultimately lost for a while, it exerted a gravitational pull on us all as we wondered whether we would see it again." (Potter)

\section{Agency of Digital Materials}

The open-source Processing 3 code which was used to randomly reconfigure the panels from the narrative collage workshop into new formats was chosen for how it might bring out new connections within the research topic beyond what had already been achieved by the human researchers. The intention was that by allowing the coding to connect the panels in seemingly random ways it might be able to find new connections between the themes that were drawn out through established processes such as thematic analysis.

For some of the group the inclusion of technology seemed apt to the original network which was also focused on technology. Further, that both the code and the VR experiences required a degree of giving up control:

"I think there are a number of reasons why the camaraderie with the workshop experience and zine go right back to the experience of the VR in Tokyo. You surrender some agency to that; you have to you. Everything from the onboarding onwards has been created by somebody, and then somebody puts the VR gear on your head and you are then in the world. So, you surrender some agency immediately... So, with the making of the zine and the workshop, a similar process occurs. So, there's a really interesting and quite dynamic parallel between the two things. The minute that the machine [code] took over... I think what it did was to surface our relationship to technology... bringing the materiality angle into the experience, acknowledging that objects and artifacts exert some agency in their entanglements with humans. " (Potter)

Rodrigues liked how the code removed the need for anyone to take control:

"It's kind of like collaborating in a very free way where we don't really know what's going to happen in the end. It's nice not to have to be in control." (Rodrigues)

Main described the relinquishing of control as providing a juxtaposition of different ideas: 
"It was juxtaposing things that you weren't necessarily thinking about so it was [useful] to see two memories side by side... before you weren't necessarily thinking of those two things together." (Main)

These five themes combine to illustrate how collaborative and playful means of working with artbased practices can highlight seemingly unimportant moments of projects, not directly related to the research topic. These are often very deliberately left out of academic research analysis and dissemination where they are unlikely to be valued. However, the methods described in this article and subsequent discussion of what they did for the VR network project suggests academics should consider why they are disregarding these moments.

The findings seem to suggest real benefits to allowing playful ways to connect researchers, to express research themes in multiple modes and to reveal less obvious connections. Also, the chance to slow down, immerse in the process of creating without an end goal. This provides a general freeing from many of the constraints placed on academic research in the UK today, that pressurise academics to produce outputs that respond to a multitude of metrics.

Fisher (2018) in response to academic writing stated that his famous K-punk blog posts became the only authentic space in which he was able to carry on writing. Potter \& McDougall (2017) call this a 'third space'. We must seek to create as many third spaces as possible to protect spaces for academic processes that do not fit the metric systems we are increasingly being forced to meet. The following quote from Rodrigues suggests this is important to the direction we are going in more widely in the world:

"So, we are kind of just playing. We don't really have an objective. We don't really know what we are doing. We are figuring it out as we go. I'm fascinated by that. It feels like a theme in the world. We are all having to try and figure out where we are going day by day and what we are going to do. It's like we need to accept and practice more not knowing” (Rodrigues)

\section{Conclusion}

This article outlines a co-production project conducted during the 2020 COVID-19 lockdown period. The intention of this project was to create a methodology for co-producing an experimental zine to understand the extent to which it would be useful as a research method for distilling and furthering the knowledge gained from a completed research study.

The narrative collage method and storyboarding process supports established research to date on how drawing, image- and mark-making methods of knowledge production can extend on, or offer an alternative to, conventional approaches to qualitative research. Focusing on coproduction, the narrative collage method not only resonated by breaking norms of isolated academic research by experiencing the process collectively and collaboratively but also encouraged finding synergies as layers of experience between the researchers shared reflections. The role of the collaborative tool had a practical purpose as intended in facilitating the recombination of the workshop responses. The participants found working with the collaborative tool analogous to their VR experiences and the role of technology, which aligned well to the study.

Supporting the arguments discussed, the intention of the collaborative tool in the process did change the hierarchy of roles, which was positive for promoting co-production. As an 
interesting adjunct to the study, this has also revealed further potential for collaborative tools to be adopted by the broader research community for mediating roles in collaborative research and especially where geographic location may be inhibitive.

The co-produced zine created as a result of the workshop process has enabled the participants to continue working with the shared data as intertextual layers and relational concepts. The round robin process of sharing has allowed individuals to reconnect and develop ideas they were unable to do either in the initial workshop or in the previously completed study. Where the initial workshop potentially limited the participants to a narrower range of drawing and image-making methods, the zine has offered an opportunity for extending methods of analysis and different modes of working. In support of the arguments discussed in this article, the methodology has proved, to an extent, that while numerous aspects of it may be contrary to academic norms, it has arguably demonstrated both originality and rigour in process, and offered new modes of representation and creating new insights to the original study.

Beyond this article the intention is to complete the round robin process of exchange by all members of the network. The limitations of the singular edition of the zine as a method has raised questions about how secure the method is and the nature of editions in the process. Concerns regarding permanently losing the original, and arguably the irreplicable data it generated, could potentially introduce an unforeseen point of consolidating and replicating, and in doing so adding additional editions to the process. While this does have some benefit in the recording and documenting of an iterative prototyping process, it also raises further questions in terms of the authenticity and mediation of the original interventions as well as how this creates an unavoidable implication for co-production in the process.

\section{References}

Adema, J. (2018) Performative publications. Media Practice and Education. 19(1).

Adema, J., Hall G. (2014) The political nature of the book: On artists' books and radical open access. Accessed: http://disruptivemedia.org.uk/thepoliticalnatureofthebook/fullarticle.html [19/02/21].

Aiello, G., Parry, K. (2019) Visual Communication: Understanding Images in Media Culture. Sage Publications, London.

Barad, K. (2003) Posthumanist performativity: Toward an understanding of how matter comes to matter. Journal of Women in Culture and Society 28(3): 801-831.

Batrack, C. (2018) Processing app to generate random comics. Accessed: https://github.com/cadin/random-comic [19/02/21].

Bezemer, J., Kress. G. (2015) Gains and Losses. In: Bezemer, J. \& Kress. G. (2015) Multimodality, Learning and Communication: A social semiotic frame. Routledge, London.

Bodman, S. (2017) Towards a community of artists' books: Extending international knowledge and debate in the field of artists' books through practice-research. (Thesis). University of the West of England. Accessed: https://uwerepository.worktribe.com/output/862355 [19/02/21].

Bodman, S., Sowden, T. (2010) A Manifesto for the Book. Impact Press, Bristol. 
Brandsen, T., Lember, V., and T nurist, P., (2019) The potential impacts of digital technologies on co-production and co-creation. Public Management Review 21 (11): 16651686.

Burkhart, A (2006) "Mongrel Nature:" A Consideration of artists' books and their implications for art education. Studies in Art Education. 47 (3): 248-268.

Bury, S. (1995) artists' books: The Book as a Work of Art, 1963-1995. Scolar Press, Aldershot.

Carrington V (2012) 'There's no going back': Roxie's IPhone: An object ethnography. Language and Literacy 14(2): 27-40.

Cohn, N. (2010) Japanese Visual Language: The Structure of Manga. In: Johnson-Woods, T. (ed.) Manga: An Anthology of Global and Cultural Perspectives: Continuum Publishing Group, London. 187-204.

Drucker, J. (1994) Visible Word. University of Chicago Press, Chicago.

Drucker, J. (2004) The Century of artists' books. Granary Books, New York.

Drucker, J. (2013) Performative Materiality and Theoretical Approaches to Interface. Digital Humanities Quarterly. 7 (1): 1-1.

Fisher, M. (2018) K-Punk: the collected and unpublished writings of Mark Fisher (20042016). Repeater Books, London.

Frost, G. (2005) Reading by Hand: The haptic evaluation of artists' books, The Bonefolder. 2 (1): $3-6$.

Ingold, T. (2013) Making: Anthropology, Archaeology, Art and Architecture. Palgrave, London \& New York.

Ingold, T. (2007) Lines. A Brief History. Routledge, London \& New York.

Kaptelinin V., Nardi B. A., and Macaulay, B. C. (1999) Methods \& tools: The activity checklist: A tool for representing the 'space' of context. Interactions 6: 27-39.

Kostera, M. (2006). The Narrative Collage as Research Method. Storytelling, Self, Society (2):5-27.

Kress, G. (2010) Multimodality. A social semiotic approach to contemporary communication. Routledge, London \& New York.

Kress, G., Van Leeuwen, T. (2003) Reading Images: the grammar of visual design. Routledge, London. 
Kulp, L. (2015) 'Teaching with artists' books: An Interdisciplinary Approach for the Liberal Arts' Art Documentation: Journal of the Art Libraries Society of North America (34): 101123.

Lyon, J. (1987) Artists' Books: A Critical Anthology and Sourcebook. Visual Studies Workshop Press, New York.

McCloud, S. (2001) Understanding Comics: The Invisible Art. William Morrow, HarperCollins, New York.

Milne, J. (2019) Artists' Books as Resistant Transmitters. Arts 8(4): 129.

Miller, D. (2009) Stuff. Polity Press, London.

Miller, D. (2008) The Comfort of Things. London: Polity Press, London.

Miller, D. (2003) Materiality: An introduction. In: Miller D (ed.) Materiality. Duke University Press, Durham, NC \& London. 1-50.

Norman, D. (2013) The Design of Everyday Things. 2nd edn. MIT Press, Cambridge. Nyholm, S. (2017) Attributing Agency to Automated Systems: Reflections on Human-Robot Collaborations and Responsibility-Loci. Science and Engineering Ethics (24): 1201-1219.

Pahl, K., Rowsell, J. (2010) Artifactual Literacies: Every Object Tells a Story. Teachers College Press, New York.

Potter, J. (2019) Six Pictures and Three Reflections. Accessed: https://ukjapanvr.wordpress.com/2019/08/15/six-pictures-and-three-reflections [18/02/21].

Potter, J., McDougall, J. (2017) Digital Media, Culture and Education: Theorising third space literacies. Palgrave Macmillan/Springer, London.

Rice (2017) Nonhumans in participatory design. CoDesign 14(3): 1-20.

Sanders, E., Stappers, P. (2007) Co-creation and the new landscapes of design. CoDesign. 2008; 4 (1): 5-18.

Sassen, R. (Ed.) (2017) Booknesses: Artists' Books from the Jack Ginsberg Collection, Johannesburg, University of Johannesburg in conjunction with the UJ Art Gallery, FADA.

Silveira, P. (2001) A Pagina Violada: Da ternura a injuria na constru ao do livro de artista. Universidade Federal do Rio Grande do Sol, Porto Alegre.

Souansis, N. (2017) Thinking in comics: an emerging process. In: Cahnmann-Taylo,r M. and Siegesmund R. (eds) Arts-Based Research in Education: Foundations for Practice, Routledge, New York \& London. 190-199.

Souansis, N. (2015) Unflattening. Harvard University Press, London. 
Shove, E., Watson M., Hand M, et al. (2007) The Design of Everyday Life. Berg, Oxford \& New York.

Thomas, S. (2009) Value and Validity of Art Zines as an Art Form. Art Documentation: Journal of the Art Libraries Society of North America, 28 (2): 27-36, 38.

Ware, G. (2010) Special Issue Prototypes: Editorial, Visual Communication. Vol. 9(3): 267272.

Yamada-Rice, D. (2021) Children's Interactive Storytelling in Virtual Reality. Multimodality \& Society, Vol.1 (1).

Young, J. E., et al (2011) Evaluating Human-Robot Interaction. International Journal of Social Robotics 3 (1): 53-67.

Zamenopoulos, T., Alexiou, K. (2018) Co-Design as Collaborative Research. In Facer, K. and Dunleavy, K. (ed.) Connected Communities Foundation Series. University of Bristol, Bristol. AHRC Connected Communities Programme.

Zetter N. (2019)' Inscription and 'Anscription': Surface and System in Cybernetics, Deconstruction, and Don DeLillo'. Humanities. 2019; 8(1): 5. 